\title{
Pediatric Preformed Metal Crown: Pedodontist's Best Friend
}

\author{
Meryem Lamrani Alaoui $^{{ }^{*}}$, Houda El Khammal ${ }^{2}$, Hakima Chhoul ${ }^{3}$ \\ ${ }^{1}$ Specialist, Department of pediatric and Preventive Dentistry- Faculty of Medical Dentistry, Mohammed V \\ university in Rabat (Morocco) \\ ${ }^{2}$ Professor assistant, Department of pediatric and Preventive Dentistry- Faculty of Medical Dentistry, \\ Mohammed V university in Rabat (Morocco) \\ ${ }^{3}$ Professor of Pediatric and Preventive Dentistry- Faculty of Medical Dentistry, Mohammed V university in \\ Rabat (Morocco)
}

*Corresponding Author: Meryem Lamrani Alaoui, Specialist, Department of pediatric and Preventive DentistryFaculty of Medical Dentistry, Mohammed V university in Rabat (Morocco).Email: m.lamrani.alaoui3@gmail.com

\begin{abstract}
Many children suffer from dental caries as the most common infectious disease. Consequently, proper dental restoration is one of the most critical issues in pediatric dentistry. Stainless steel crowns (SSCs) are characterized by full crown coverage and increased caries prevention through protecting the entire tooth; they are also more durable than multisurface amalgam restorations.

Compared to alternative restorative materials, the SSC should continue to be recognized for its efficiency, costeffectiveness, and successful treatment modality.
\end{abstract}

Keywords: Pediatric Preformed Metal Crown, pedodontist, primary, tooth.

\section{INTRODUCTION}

The primary dentition plays a very important role in the child's growth and development, not only in terms of speech, chewing, aesthetic and the prevention of bad habits but also in the guidance and eruption of permanent teeth [1].

Exfoliation of primary teeth and eruption of permanent teeth is a normal physiological process [2]. When this normal process is disrupted, due to factors like premature loss of primary teeth, proximal carious lesions etc, may lead to mesial migration of teeth resulting in loss of the arch length which may manifest as malocclusion in permanent dentition in the form of crowding, impaction of permanent teeth, supraeruption of opposing teeth etc [3].

Once the primary tooth is decayed, the best way to avoid these problems is to restaure it. Hence the SSC serve as best restoration which preserve the primary teeth in the arch till their normal time of exfoliation is attained [4].

\section{CASE REPORT}

A 4-year-old healthy female was referred to the pediatric and preventive dentistry department in the consultation department of the consultation and dental treatment center of Rabat. She gaves a History of antecedent night spontaneous dental pain in the right mandibular area.

In the anamnesis the patient's mother reported that the patient had the habit of eating sugary foods throughout the day. No significant past medical or dental family history was reported.

The clinical examination revealed that the patient have a temporary entition with intact teeth in the maxillary arch and in the mandibular arch, teeth \#75, \#85, showed an enamel breakdown and soft cavity in dentin [Figure 1-2].

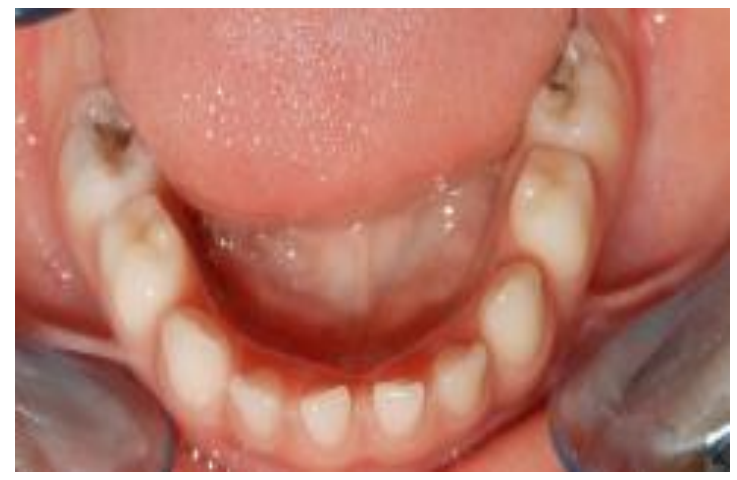

Figure1: Occlusal view showing carious lesions in 74 and 85 . 


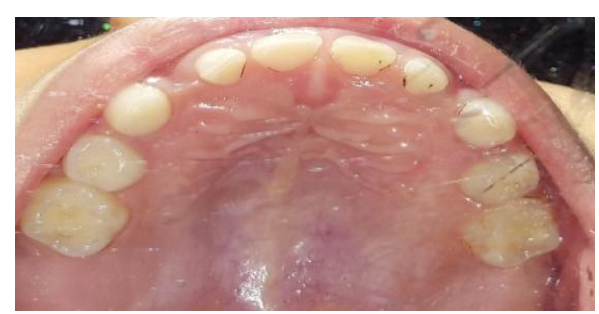

Figure2: Occlusal view showing the clinical aspect of the maxillary arch (free of cavities).

Radiographic examination showed a radiolucent lesion in contact of the pulp on \#85 and \#75 exhibited carious lesion on the inner half of dentine. This radiographic examination matched with the clinical diagnosis of early childhood caries (ECC) [Figure 3-4]

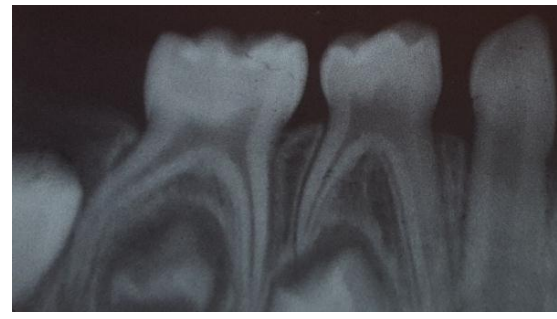

Figure3: Radiographic examination showing radiolucent lesion in contact of the pulp \#85

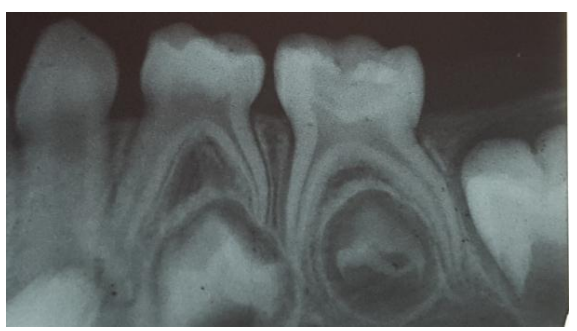

Figure4: Radiographic examination evidencing carious lesions at the inner half of the dentine of 75

The treatment plan was decided and explained to the mother and parental consent was taken. On first visit, the child was unfamiliar with the dental environment. The child was made comfortable with dental equipments and behavior management was done by application of tellshow-do technique.

Initially, assessment of personal oral hygiene was performed and home care instructions including oral hygiene and diet counseling were given to the mother.

Professional prophylactic cleaning of dental surfaces as an initial approach was done in the first sitting. In the next visit the food dairy was checked and the patient was found to be adhering to the counseled diet changes and the oral hygiene measures were reinforced.

Then we started by pulpotomy treatment for tooth \#75 and the cement of glass ionomer (GIC) composite restoration was performed [Figure 5$6]$.

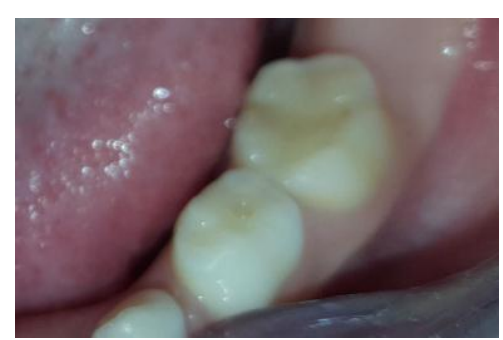

Figure5: Pulpotomy treatment for tooth \#75 and Glass Ionomer Cement -composite restoration

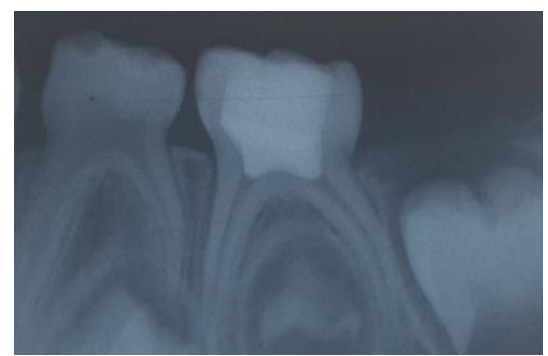

Figure6: Post operative radiograph. Pulpotomy in \#75

Pulpectomy was planned in 85 followed by stainless steel crown (SSC) for occlusal rehabilitation [Figure 7: a,b].
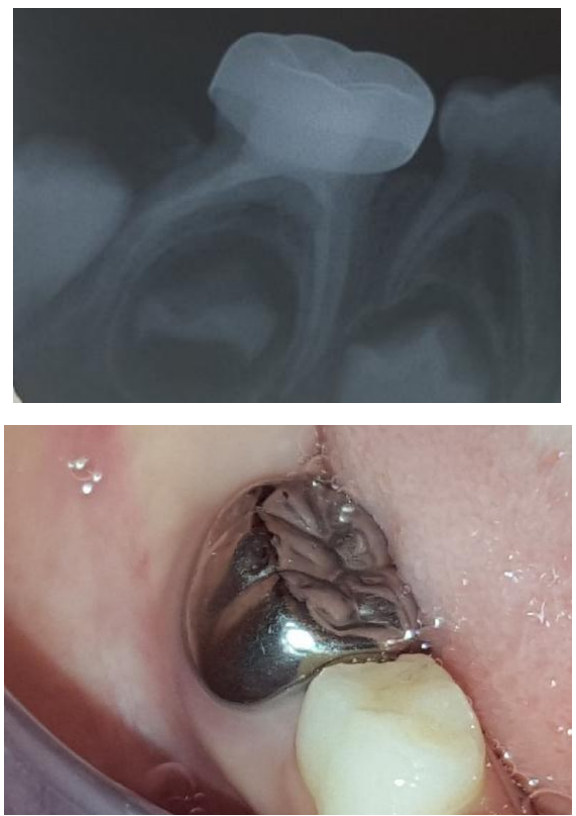

Figure7: (a) Post operative $X$-ray showing the Pulpectomy in 85 (b) occlusal rehabilitation by stainless steel crown (SSC)

Concurrently, recommandations were given to the family concerning the use of fluoridated tooth paste and about proper oral hygiene practices.

Recall check-up was scheduled for every 6 months to check the status of exfoliation of the primary teeth, eruption of permanent teeth, the health status of the periodontal tissues, and compliance with control measures for caries. At follow-up examination after 6 months, the restorations remained intact and no further caries were detected [Figure 8]. 


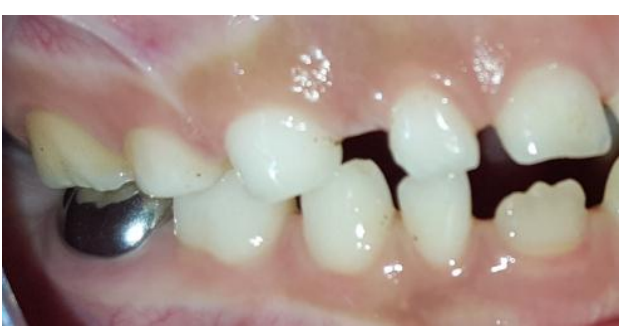

Figure8: Follow-up examination after 6 months: the restorations remained intact and no further caries were detected

At 18 months, the lower right first permanent molar began to erupt [Figure 9]. After 24 months, the patient demonstrated improved cooperation. She had no new carious lesions and had good oral hygiene. On the other hand, the all first permanent molars were erupted completely and they were sealed by a sealant based on resin [Figure 10: a, b, c, d]. At 4 years follow up examination, the SSC as well as the pit and fissures sealants remained intact [Figure 11: a, b].

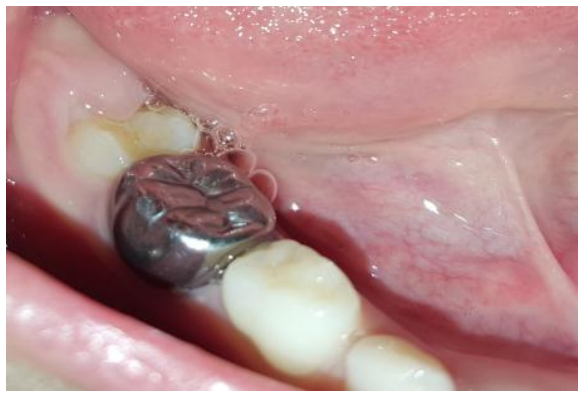

Figure9: 18 months later. 46 began to erupt

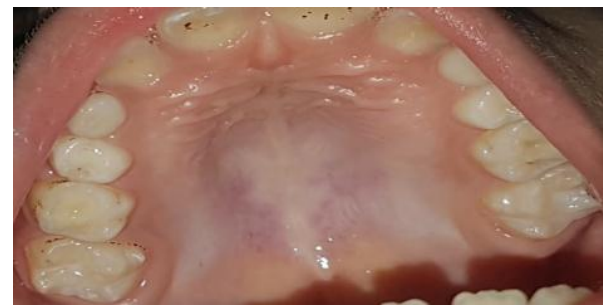

(a)

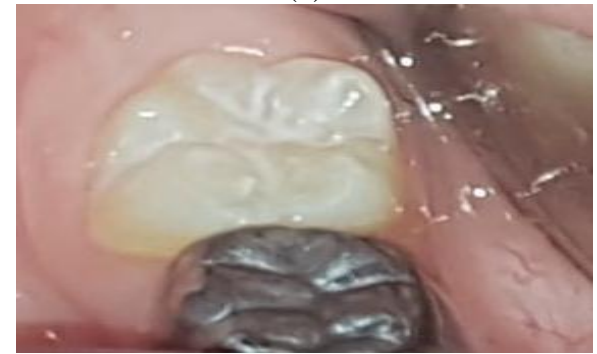

(b)

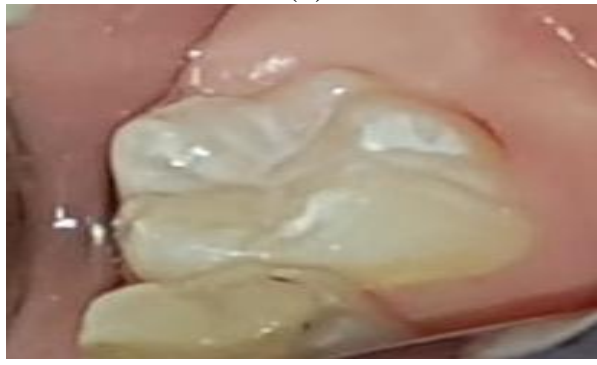

(c)

ARC Journal of Dental Science

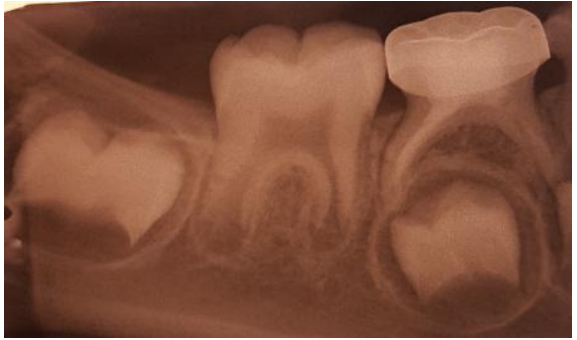

(d)

Figure10 (a, b, c, d): 24 months follow-up: Intraoral photograph showing \#46, 3616 and 26 sealed and the SSC fulfilled its role as best guide for permanent molar eruption, (d) X-ray follow-up: good evolution of teeth.
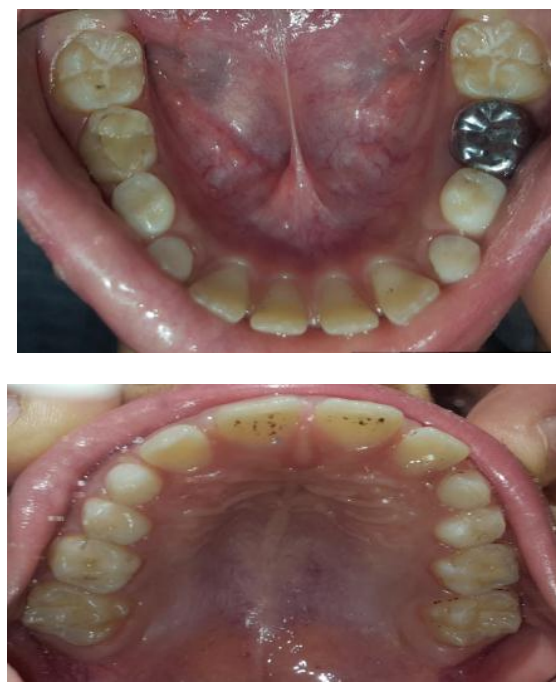

Figure11(a, b): 4 years follow up: intact restorations of mandibular and maxillary arch

\section{DISCUSSION}

In order to prevent arch length changes, the best space maintainer is a well maintained primary tooth, as all space maintainer appliances are plaque retentive, thereby placing patients at a greater risk of developing caries and gingival inflammation. Space maintainer appliances may also impinge on the soft tissues, interfere with the eruption of adjacent teeth, fracture, and become dislodged or lost.

Therefore, every effort should be made to retain primary molars until they are naturally exfoliated [5].

In our case, we attempt to maintain 85 as long as possible by means of SSC restoration so as to guide the successor and adjacent permanent teeth.

Rehabilitation of affected primary/young permanent teeth by means of stainless steel crowns (SS crown) has become a viable assistance to the Pediatric Dentist ever since Rocky Mountain Company introduced them in 1947 but familiarized by Humphrey and Engel in 1950s. They are prefabricated shells crowns in 
different sizes, composed of Nickel: $76 \%$, Chromium: $15 \%$, Iron: $8 \%$, Carbon: $0.08 \%$, Manganese: $0.35 \%$, Silicon: $0.2 \%$ [6].

In general, crowns are routinely used for restoring pulp-treated teeth. The SSC on weakened 85 following pulpectomy procedure, obey to the concept of full coverage and eliminate the risk of breaking tooth to buccal and lingual halves due to reduced dentin strength.

Another indication of SSCs is dental treatment under general anesthesia. In dental rehabilitation under general anesthesia, the approach is to restore teeth more with SSCs and less with other dental materials [7]. Children with hypophosphatemia, who develop spontaneous dental abscesses, are also among cases requiring SSCs [8].

Other indications include heritable dental defects, such as amelogenesis imperfecta, dentinogenesis imperfecta, environmentallyinduced defects such as enamel hypoplasia enamel hypoplasia (Molar Incisor Hypomineralization $\mathrm{MIH}$ ), and restoration / protection of teeth exhibiting extensive tooth surface loss due to attrition, abrasion or erosion [9].

In pediatric dentistry, the strategy is to deliver efficient treatment and simultaneously reduce the time of operation. Application of SSCs reduces the time of operation and promotes the child's cooperation. In fact, compared to other restoration methods, SSCs placement is less disturbing for the patient. SSCs are also durable, relatively inexpensive [10].

Despite various advantages of crowns, there is a compromise in esthetics due to the unsightly silver metallic appearance [11]. Furthermore, microleakage occurs in the marginal area due to the prefabricated entity. [12].

However, these drawbacks are not critical, compared to various advantages of crowns and to mask the metallic appearance of crowns, a modification, called pre-veneered SSC, is available [13].

SSC are often used to restore primary and permanent teeth in children and adolescents where intracoronal restorations would otherwise fail [14].

SSCs are not recommended in a patient with a known nickel allergy or sensitivity and on the tooth that will be soon exfoliated and when the $\mathrm{X}$-ray examination shows that resorption exceeds half of the root $[15,16]$.

\section{CONClusion}

All available evidence suggests that the stainless steel crown enjoys a wide range of use in clinical pedodontics and should continue to be used to restore primary and permanent molars teeth in young children.

\section{REFERENCES}

[1] Barberia E, Lucavechi T. Free end Space Maintainers: Design Utilisation and Advantages. J Clin Pediatr Dent. 2006; Fall; 31 (1) 5-8.

[2] Rao AK, Sarkar S. Changes in arch length following premature loss of deciduous molars. $\mathrm{J}$ Indian Soc Pedo Prev Dent. 1999; March:28-32.

[3] http://depts.washington.edu/peddent/AtlasDem o/space009.html

[4] Kirzioglu Z, Ozay MS Z, Ozay MS. Success of reinforced fibre material space maintainers. J Dent Child. 2004;71;2:158-62.

[5] Kanika Gupta. Space Maintainers: A Stitch in Time. Journal of Dentistry and Oral Biology. 2018 | Volume 3 | Issue 3 | Article 1130.

[6] Donly KJ, Godoy KJ. The use of resin-based composite in children. Pediatric Dentistry 2002; 24(5): 480-488.

[7] Ramazani N. Different Aspects of General Anesthesia in Pediatric Dentistry: A Review. Iran J Pediatr. 2016;26(2):2613.

[8] Ramazani N. Hypophosphatemic rickets and its dental significance. Iran J Pediatr. 2013; 23(6) :714.

[9] Full CA, Walker JD, Pinkham JR. Stainless steel crowns for deciduous molars. J Am Dent Assoc $1974 ; 89 ; 360-364$.

[10] Seale NS. The use of stainless steel crowns. Pediatric Dentistry 2002; 24(5):501-505.

[11] Lee JK. Restoration of primary anterior teeth: review of the literature. Pediatr Dent 2002;24:506-10.

[12] Zarenejad N, Asgary S, Ramazani N. Coronal microleakage of three different dental biomaterials as intra-orifice barrier during nonvital bleaching. Dent Res J (Isfahan). 2015;12(6):581-8.

[13] Veerakumar.R, Pavithra.J, Keerthana Sekar.G. Esthetic Crown In Paediatric Dentistry: A Review. International Journal of Innovations in Dental Sciences / August 2017 / Vol 2 / Issue 2.

[14] Threfall AG, Pilkington L, Milsom KM et al. General dental practitioners' views on the use of stainless steel crowns to restore primary molars. Br Dent J 2005; 199:453-455. 
[15] Roberts JF, Sherriff M. The fate and survival of amalgam and preformed crown restorations placed in a paediatric dental practice. Br Dent $\mathbf{J}$ 1990; 169: 237-244.
[16] Curzon MEJ, Roberts JF, Kennedy D. Kennedy's paediatric operative dentistry. 4th ed. Oxford: Butterworth-Heinemann, 1996. pp 7987, 114-127.

Citation: Meryem Lamrani Alaoui, Houda El Khammal, Hakima Chhoul. Pediatric Preformed Metal Crown: Pedodontist's Best Friend. ARC Journal of Dental science. 2019; 4(3):1-5. doi:dx.doi.org/ 10.20431/24560030.0403001 .

Copyright: (c) 2019 Authors. This is an open-access article distributed under the terms of the Creative Commons Attribution License, which permits unrestricted use, distribution, and reproduction in any medium, provided the original author and source are credited. 